\title{
A Study on the Technological Innovation Efficiency and Influencing Factors of Iron and Steel Enterprises Based on DEA - Tobit Two-step Method
}

\author{
Baihua $\mathrm{Li}^{1, \mathrm{a}}$, Junyin Yan ${ }^{1, \mathrm{~b}}$, Gang Wang ${ }^{2, \mathrm{c}}$ \\ ${ }^{1}$ Hebei GEO University, Department of science and technology, Shijiazhuang, Hebei, China \\ ${ }^{2}$ Faculty of Graduate Studies, Shijiazhuang Tiedao University, Shijiazhuang, Hebei, China \\ alibaihua09@163.com, byanjy@sjzedu.cn, '1029549936@qq.com
}

Keywords: Iron and steel enterprises, Technological innovation efficiency, DEA, Tobit model.

\begin{abstract}
The article analyzes the resource input of iron and steel enterprises in their technological innovation process by setting the input-oriented DEA effective frontier with the DEA method. On this basis, the regression analysis is carried out with respect to the influencing factors of the technological innovation efficiency in iron and steel enterprises with the Tobit regression analysis method. The study results show that (1) the averaged technological innovation efficiency of 12 enterprises is only 0.774 , indicating the overall technological innovation efficiency of iron and steel enterprises is low; (2) Overall, the contribution of the pure technical efficiency is greater than the scale efficiency, and the scale efficiency of iron and steel enterprises is generally low; (3) There is a big difference in the technological innovation efficiency of different iron and steel enterprises; (4) The industrial structure and the overall innovation environment of the region where an enterprise is located play an important promoting role in the improvement of the technological innovation efficiency of iron and steel enterprises; (5) Increasing the concentration of production capacity, improving the innovation and resource allocation in the process of technological innovation, and optimizing the regional industrial structure and regional innovation environment, is the effective way to effectively improve the technological innovation efficiency of iron and steel enterprises.
\end{abstract}

\section{DEA-Tobit Two-step Method}

The DEA-Tobit two-step analysis method is an evaluation method derived from DEA analysis, which includes two-step extended analysis. The first step is to evaluate the technological innovation efficiency of each evaluation unit (DMU) through use of the DEA model; and the second step is to carry out the regression analysis by taking the DEA efficiency as the dependent variable, and the selected influencing factors as the independent variables, and to determine the influence degree on the efficiency value and change direction of all the influencing factors according to the measured independent variables, and identify the sensitive factors of the technological innovation efficiency, so as to provide guidance for the scientific planning of corresponding policies and recommendations.

The Data Envelopment Analysis (DEA) can directly calculate the relative effective frontier of multiple decision units (DMUs) by using the evaluation data and mathematical programming model, thus achieving the effective evaluation on the relative efficiency of DMUs. After many years of research and development, the DEA model has evolved from the initial CCR model to BCC, and then extended to the super efficiency model and other models. Different models have different application conditions and assumptions, thus, can reflect different evaluation aspects of an evaluation object. When calculating the efficiency frontier with DEA, two methods may be used, i.e. the input-oriented method and the output-oriented method. Considering the production characteristics of iron and steel enterprises, we choose the input-oriented DEA model to study the innovation efficiency. 
As for the CCR model, it is assumed that each DMU has a fixed "Returns to Scale", and its input-oriented model can be expressed as:

$$
\begin{aligned}
& \min \theta \\
& \left\{\begin{array}{l}
\sum_{j=1}^{\mathrm{n}} \mathrm{X}_{j} \lambda_{j} \leq \theta \mathrm{X}_{0} \\
\sum_{j=1}^{\mathrm{n}} \mathrm{Y}_{\mathrm{j}} \lambda_{\mathrm{j}} \geq \mathrm{Y}_{0} \\
\lambda_{\mathrm{j}} \geq 0 \quad \mathrm{j}=1, \cdots, \mathrm{n}
\end{array}\right.
\end{aligned}
$$

Where, $\theta$ is the effective value of the decision unit, and if $\theta=1$, then the DEA of the decision unit is valid.

DEA is in the CCR, but the further analysis on the effective unit cannot be achieved, which shows certain limitations of evaluation. The Super Efficiency is the expanded model of DEA evaluation, according to which, the DMU efficiency ranking may be achieved. The efficiency value of the super-efficiency model may be greater than 1 , indicating the maximum ratio of the DMU input when the validity is maintained, while the efficiency value of the ineffective DMU in the super efficiency is the same as the efficiency value in the DEA basic model ${ }^{[4]}$. The difference between the super-efficiency model and the standard model is that during the efficiency evaluation of $\mathrm{DMU}_{\mathrm{i}}$ all the other DMU inputs and outputs are linearly combined, to substitute $\mathrm{DMU}_{\mathrm{i}}$, thus excluding the same. In this case, the super-efficiency model can be expressed as:

The Tobit model, also known as censored regression model, is proposed for the dependent variables that are partially continuously distributed or partially dispersedly distributed. The model can be expressed as:

$$
\begin{aligned}
& \min \theta \\
& \left\{\begin{array}{l}
\sum_{\substack{j=1 \\
j \neq k}}^{n} X_{j} \lambda_{j} \leq \theta X_{k} \\
\sum_{\substack{j=1 \\
j \neq k}}^{n} Y_{j} \lambda_{j} \geq Y_{k} \\
\lambda_{j} \geq O \quad j=1, \cdots, n
\end{array}\right.
\end{aligned}
$$

Where, $\mathrm{Y}_{\mathrm{i}}$ is a dependent variable, i.e. the efficiency value of DEA ; $\mathrm{X}_{\mathrm{i}}$ is a dependent variable, i.e. the explanatory variable that influences the efficiency value; and $\varepsilon$ is the random error vector. Since the efficiency value of DEA is a discrete value greater than 0 , if the ordinary least square method is used to estimate the model parameters, there will be a certain error. Therefore, the maximum likelihood method should be used to estimate the Tobit model parameters, and the more accurate fitting result can be obtained.

\section{Indicator System}

Based on the analysis and evaluation of technological innovation efficiency of micro-iron and steel enterprises, a total of 12 domestic representative iron and steel enterprises are selected this time, including Anyang Iron \& Steel Inc., Anshan Iron \& Steel Corp, Baotou Steel Union Co., Ltd., Baoshan Iron \& Steel Co., Ltd., Jinan Iron \& Steel Corp, Maanshan Iron \& Steel Corp, Shougang Group, Taiyuan Iron \& Steel (Group) Co., Ltd., Tangshan Iron \& Steel Group, Wuhan Iron and Steel Company Limited and Chongqing Iron \& Steel Company Limited. The data is from the 2012 annual report of these enterprises’ production and business activities.

Based on the combination of studies of all the relevant scholars on the evaluation indicator 
system of technological innovation efficiency, this article fully considers the factors closely related to the technological innovation efficiency of iron and steel enterprises, focusing on the presentation of technological innovation effects of iron and steel enterprises while taking into account the economic benefits of the enterprises, to determine the evaluation indicator system for the technological innovation efficiency of iron and steel enterprises. Input indicators: (1) Proportion of R \& D input in the sales revenue of products; (2) Number of R \& D staff; (3) Amount of investment in technological transformation; output indicators: (1) Proportion of new product output in the sales revenue; (2) Number of enterprise patents;(3)Number of published papers.

\section{DEA Evaluation of Technological Innovation Efficiency of Iron and Steel Enterprises}

Based on the input-oriented analysis method, the technological innovation efficiencies of all the iron and steel enterprises are analyzed and evaluated through the CCR, BCC and super-efficiency models of DEA, via the DEA software MaxDEA, combined with the characteristics of iron and steel enterprises and according to the selected evaluation indicator system.

Table 1 Efficiency Values of CCR Model for Technological Innovation Efficiency of Iron and Steel Enterprises

\begin{tabular}{ccccccc}
\hline Enterprise & Anyang & Anshan & Baotou & Baoshan & Jinan & Maanshan \\
\hline $\begin{array}{c}\text { Efficiency } \\
\text { Value }\end{array}$ & 0.246 & 0.608 & 0.548 & 0.764 & 0.801 & 0.627 \\
\hline Enterprise & Panzhihua & Shougang & Taiyuan & Tangshan & Wuhan & Chongqing \\
\hline $\begin{array}{c}\text { Efficiency } \\
\text { Value }\end{array}$ & 1 & 1 & 0.704 & 0.986 & 1 & 1 \\
\hline Accoren
\end{tabular}

According to the efficiency values of the CCR model (Table 1), it can be seen that only the technological innovation efficiencies of Panzhihua Steel Group Co.,Ltd., Shougang Group, Wuhan Iron and Steel Company Limited and Chongqing Iron \& Steel Company Limited of all the selected 12 domestic iron and steel enterprises, have realized the DEA is valid in the technological innovation efficiency, thus achieving the effective coupling between the innovation input and output, and the rest of the iron and steel enterprises have shown varying degrees of inefficiency. From the average value of the efficiency point of view, the average efficiency of the 12 selected domestic iron and steel enterprises is 0.774 . A total of seven enterprises have an efficiency value above the average, accounting for about $58.3 \%$, and all the remaining five enterprises have a technological innovation below the average, showing the technological innovation efficiency of domestic iron and steel enterprises is not optimistic.

The super efficiency value refers to the value at which the efficiency is maintained as relatively effective when all the input factors are increased by an equal ratio. For the enterprises whose DEA is not invalid in the super-efficiency model, their super efficiency values are the same as the efficiencies evaluated in the basic DEA model. While for the iron and steel enterprises that realize the validity of DEA, the super efficiency value may be used to calculate their super efficiency value (greater than 1). On this basis, the difference between the iron and steel enterprises whose DEA is valid may be further analyzed.

Table 2 Efficiency Values for Technological Innovation Efficiency Model

\begin{tabular}{ccccccc}
\hline Enterprise & Anyang & Anshan & Baotou & Baoshan & Jinan & Maanshan \\
\hline Super & 0.246 & 0.608 & 0.548 & 0.764 & 0.801 & 0.627 \\
\hline Ranking & 12 & 10 & 11 & 7 & 6 & 9 \\
\hline Enterprise & Panzhihua & Shougang & Taiyuan & Tangshan & Wuhan & Chongqing \\
\hline Super & 2.058 & 5.378 & 0.704 & 0.986 & 4.031 & 3.564 \\
\hline Ranking & 4 & 1 & 8 & 5 & 2 & 3 \\
\hline
\end{tabular}




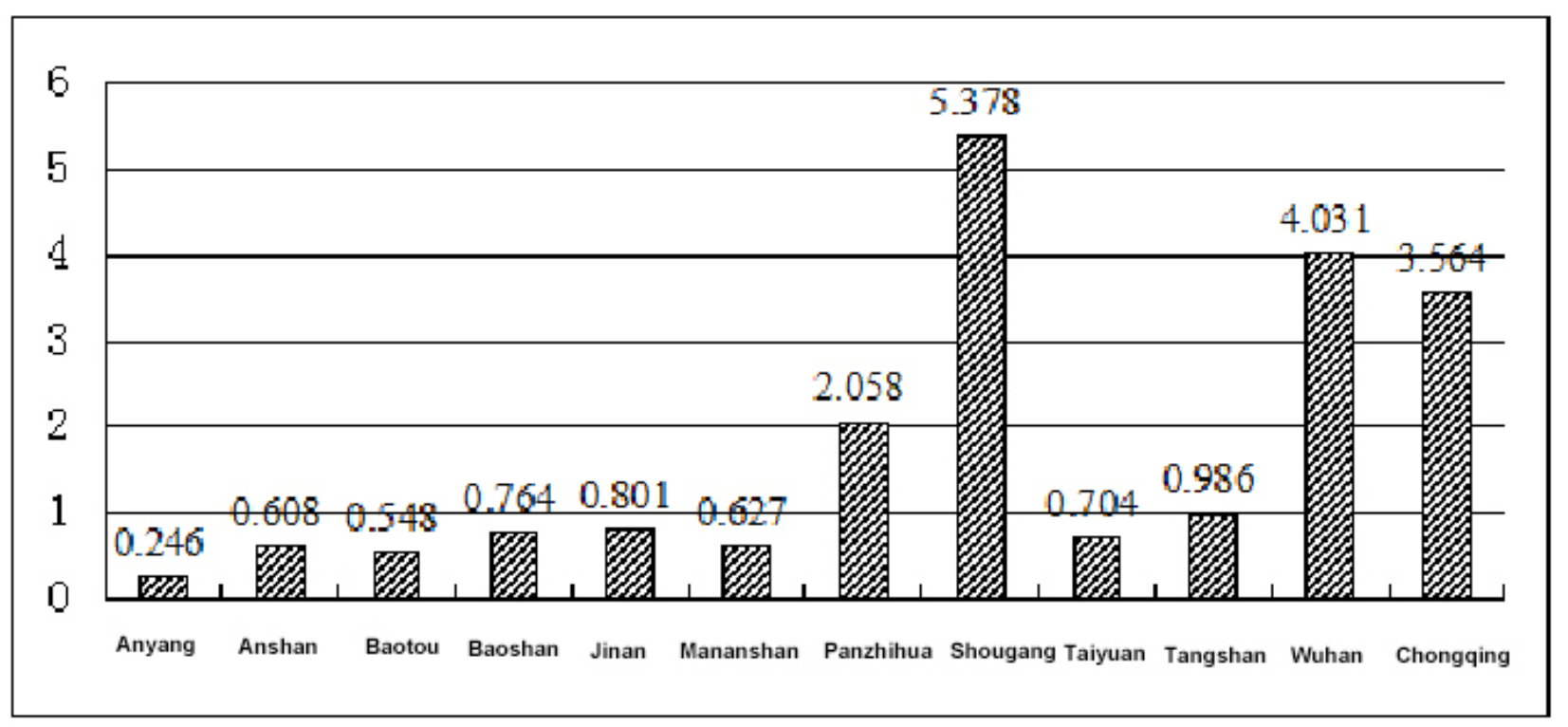
Fig.1 Analysis Results Chart for Technological Innovation Efficiency Model of Iron and
Steel Enterprises

From Table 2 and Fig.1, it can be seen that Shougang Group has the highest technological innovation efficiency value, i.e. 5.378, which means that the input factors of Shougang Group have been increased by an equal ratio of $437.8 \%$, and it can still maintain the relative validity of the efficiency, indicating it still has a large development potential in terms of technological innovation; Wuhan Iron and Steel Company Limited is secondary to Shougang Group, the super efficiency value is 3.031. Through the super efficiency value, the 12 iron and steel enterprises may be further ranked in terms of the efficiency. The results show that Shougang Group ranked first, Wuhan Iron and Steel Company Limited ranks second, Anyang Iron \& Steel Inc., Anshan Iron \& Steel Corp and Baotou Steel Union Co.,Ltd. rank the last. There is a big gap compared to Shougang Group, Wuhan Iron and Steel Company Limited, Chongqing Iron \& Steel Company Limited and Panzhihua Steel Group Co.,Ltd..

\section{Tobit Analysis on the Influencing Factors of the Technological Innovation Efficiency of Iron and Steel Enterprises}

\subsection{Selection of Influencing Factors}

By summarizing relevant literature, and combining with the Annual Report of Regional Innovation Capability of China (2012), this article selects the economic scale, industrial structure, innovation base and innovation environment as the factors influencing the technological innovation efficiency of iron and steel enterprises, from the perspectives of economic operation and regional environment. Where, the proportion of GDP of the province in which the iron and steel enterprise is located relative to the national GDP $\left(\mathrm{X}_{1}\right)$ indicates the economic scale; the proportion of the industrial output of the province in which the iron and steel enterprise is located relative to the regional GDP $\left(\mathrm{X}_{2}\right)$ indicates the industrial structure; the proportion of the innovation expenditure of the province where the iron and steel enterprise is located relative to GDP $\left(\mathrm{X}_{3}\right)$ as well as the proportion of the people having the education of junior college and above in every 100,000 people $\left(\mathrm{X}_{4}\right)$ indicate the innovation environment; and the proportion of the regional technology turnover of the province in which the iron and steel enterprise is located relative to the national turnover $\left(\mathrm{X}_{5}\right)$ indicates the innovation base. 


\subsection{Tobit regression analysis}

The Tobit regression analysis is carried out on influencing factors of the technological innovation efficiency of enterprises by taking factors by taking the technological innovation efficiency value of iron and steel enterprises as the dependent variable and the selected influencing factors on the above-mentioned five aspects, based on the data from the China Statistical Yearbook and the Annual Report of Regional Innovation Capability of China (2012)(Table 5).

Table 3 Tobit Regression Analysis Results of Influencing Factors for the Technological Innovation Efficiency of Enterprises

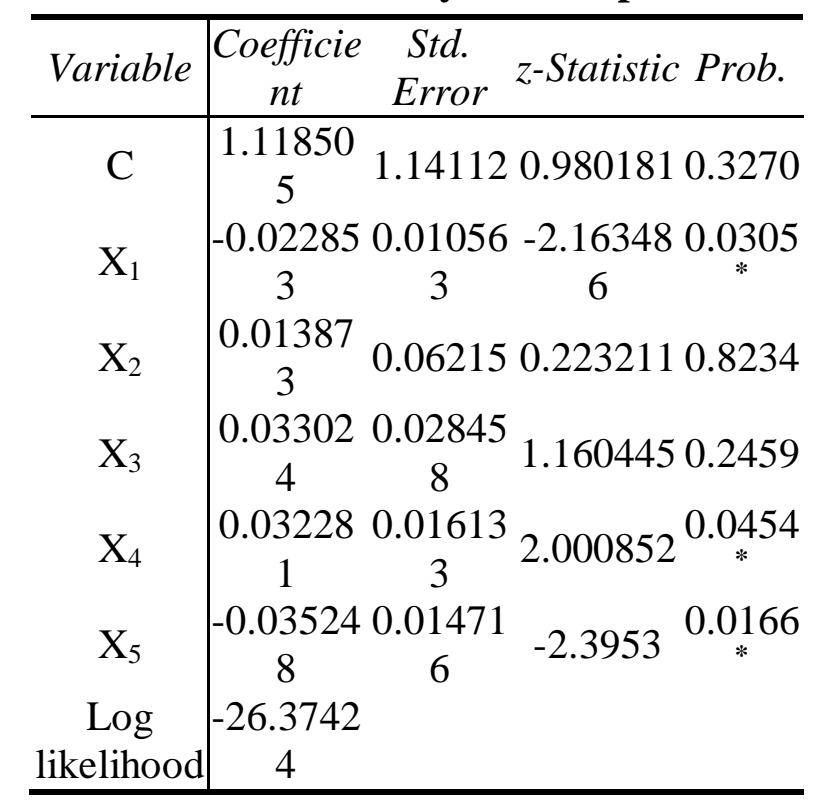

Note: * indicates that the estimated coefficient is significant at the confidence level of $5 \%$.

From the results of Tobit analysis, it can be seen that among the five factors that influence the technological innovation efficiency of iron and steel enterprises, the regional economic scale factor reflected by the proportion of GDP of the province in which the iron and steel enterprise is located in $\left(\mathrm{X}_{1}\right)$ is negatively correlated to the technological innovation efficiency at the significant level of $5 \%$, indicating that the expansion of economic scale will reduce the level of technological innovation efficiency to a large extent. In terms of innovation environment, the proportion of the people having the education of junior college and above in every 100,000 people $\left(\mathrm{X}_{4}\right)$ is positively correlated to the technological innovation efficiency at the significant level of $5 \%$, indicating that the improvement of regional labor quality is conducive to promoting technological innovation efficiency of iron and steel enterprises, and also indicating that the labor quality will have a large influence on the enterprises' technological innovation activities as the result of development in the knowledge-intensive technological innovation efficiency. The proportion of the regional technology turnover of the province in which the iron and steel enterprise is located relative to the national turnover $\left(\mathrm{X}_{5}\right)$ is negatively correlated with the technological innovation efficiency at the significant level of 5\%, indicating that the existing innovation base can enhance the awareness of technological innovation efficiency of iron and steel enterprises, but which often results in the input redundancy in the production process, causing the reduction of efficiency, and affecting the improvement of the overall technological innovation efficiency. In addition, the proportion of the industrial output of the province in which the iron and steel enterprise is located relative to the regional GDP $\left(\mathrm{X}_{2}\right)$ as well as and the proportion of the innovation expenditure of the province where the iron and steel enterprise is located relative to GDP $\left(\mathrm{X}_{3}\right)$ have a certain positively-correlated influence on the improvement of 
the enterprises' technological innovation efficiency, but this influence is not significant. The adjustment and upgrading of industrial structure, especially the promotion and development of high-tech industry, is conducive to promoting the enhancement level of the regional technological innovation, and the development of technological innovation capability of iron and steel enterprises. However, this kind of influence on the industrial structure generally plays a basic promoting role, and cannot form significant influence; the inclinations in policies and funds brought by the government support can provide a good policy environment for the improvement of the enterprises' technological innovation efficiency. Similarly however, this kind of policy support factor cannot have a key influence on the development and breakthrough of the technological innovation of iron and steel enterprises.

\section{Conclusion and Countermeasures}

With the DEA and Tobit regression methods, this article carried out a systematic analysis on the technological innovation efficiency and its influencing factors domestic iron and steel enterprises, and has drawn the following conclusions:(1) Of the 12 selected domestic iron and steel enterprises, only the technological innovation efficiency of Panzhihua Steel Group Co.,Ltd., Shougang Group, Wuhan Iron and Steel Company Limited, Chongqing Iron \& Steel Company Limited is valid in DEA, accounting for one-third of all the evaluated objects. The averaged technological innovation efficiency of the 12 enterprises is only 0.774 , indicating the overall technological innovation efficiency of China's iron and steel enterprises is low; (2) Through the further analysis on the super efficiency model, it is found there is a big difference in the technological innovation efficiency of the iron and steel enterprises, with the highest value of 5.375 and the lowest value of only 0.246. The overall efficiency of Shougang Group, Wuhan Iron and Steel Company Limited, Chongqing Iron \& Steel Company Limited and Panzhihua Steel Group Co.,Ltd. is significantly higher than the other enterprises; (3) and the Tobit regression analysis shows that the industrial structure and the overall innovation environment of the region where the enterprise is located play a high promoting role in the improvement of the technological innovation efficiency of iron and steel enterprises, while the regional overall economic scale and innovation base have no significant influence.

In view of the above conclusions, the following countermeasures and suggestions are put forward: Firstly, optimize the productivity layout of the iron and steel industry and continuously improve the concentration of production capacity. Take the macro-control on the production capacity of the iron and steel as an opportunity to help excellent enterprises and eliminate inferior ones, so that the concentration of the production capacity of iron and steel enterprises is continuously improved, and the scale efficiency is fully achieved; Secondly, strengthen the enterprise management, optimize the innovative resources allocation in the enterprise's production process, and actively carry out the management and control on the innovation resources in the enterprise's innovation process, improving the overall technological innovation efficiency; and thirdly, adjust the regional relevant policy system, and constantly optimize the regional industrial structure and innovation environment. As the supporting countermeasures, develop the regional relevant policies and perfect the same systematically on the basis of transforming the economic development form, with improving the regional innovation capacity as the goal, optimize the industrial structure and regional innovation environment, build good technological innovation conditions and innovation environment, to provide the guarantee for the enhancement of technological innovation efficiency of iron and steel enterprises ${ }^{[8]}$;

\section{Acknowledgement}

Funding: Youth Foundation Project of HeBei GEO university (201711) 


\section{References}

[1] Chen Hongmei and Ning Yucai. Evaluation of China's provincial technological innovation efficiency and comparative study [J]. Inquiry into Economic Issues, 2011 (8): 66-70

[2] Zhang Qinghui and Wang Jianguo. DEA-based evaluation of China's high-tech industry independent innovation efficiency [J]. Scientific Management Research, 2011 (10): 9-13

[3] Guo Lei and Liu Zhiying. Study on evaluation of regional technology innovation efficiency based on DEA cross efficiency model [J]. Science of Science and Management, 2011 (11): 138-143

[4] Li Wuwei. Evaluation of China' Industrial Technology Innovation Efficiency [J]. Scientific Management Research, 2009 (7): 151-154

[5] Bai Junhong, Jiang Keshen, Li Jing, et al. Analysis of Environmental Impact Factors of Regional Innovation Efficiency - Empirical Test Based on DEA Tobit Two-step Method [J]. Research and Development Management, 2009 (2): 96-101

[6] Guan Xiangyong and Wang Zhengbin. Empirical Study on the Influence of Regional Innovation Environment on Regional Innovation Efficiency [J], Scientific Management Research, 2011 (21): 16-23. 